\title{
Análise de rótulos de macarrões integrais de acordo com a legislação em relação ao teor de fibra e informações obrigatórias
}

Ana Paula Bastos Sousa Sales anapaulabastos.ana@gmail.com http://orcid.org/0000-0003-2264-9858 Fortaleza, Ceará, Brasil.

\section{Wellingtânia Bastos Cruz} Rodrigues

wellingtania.rodrigues@hotmail.com http://orcid.org/0000-0001-6347-6717 Centro Universitário Fametro, Unifametro, Fortaleza, Ceará, Brasil.

Priscila Pereira Pessoa priscilapessoanutricionista@gmail.com Centro Universitário Fametro, Unifametro, Fortaleza, Ceará, Brasil.

\author{
RESUMO
}

Diante do desenvolvimento que vem acontecendo na área alimentícia, gera-se a necessidade de garantir informações úteis e confiáveis em rótulos de alimentos. Este estudo teve como objetivo analisar rótulos de macarrões integrais em relação ao teor de fibras e informações obrigatórias, conforme legislações vigentes. Tratase de um estudo de caráter descritivo de abordagem quantitativa realizado na cidade de Fortaleza-Ceará. Foram analisadas 21 marcas, nas quais se observou às quantidades de fibras descritas nos rótulos. Foi desenvolvido e aplicado checklist pertinente às seguintes legislações: RDC no 54/12; RDC no 259/02; RDC no 360/03 e a lei 10.674/03. Quanto à RDC no 54/12, 70,8\% dos rótulos analisados correspondiam ao critério para alegação de "alto conteúdo de fibra" e 29,1\% para "fonte de fibra". Em relação às legislações para alimentos embalados, sete marcas apresentaram não conformidade. Encontravam-se inadequados itens da RDC no 259/2002: o uso de um sinal e uma denominação que poderia levar o consumidor ao equívoco; a atribuição de propriedades que não podem ser demonstradas; a indicação que possui propriedades medicinais ou terapêuticas e a ausência de instrução de preparo. Em relação à RDC no 360/03 apenas um produto apresentou letra ilegível. Verificou-se conformidade em $100 \%$ das marcas quanto à Lei 10.674/03 referente ao glúten. Conclui-se que os rótulos avaliados, em sua maioria estão em conformidade com as legislações vigentes, sendo $69 \%$ em acordo quanto a RDC no 259/02 e 96\% quanto a RDC no 360/03. São indispensáveis fiscalizações rígidas, uma vez que o consumidor precisa ter informações fidedignas dos produtos comercializados.
\end{abstract}

PALAVRAS-CHAVE: Massa alimentícia; rotulagem de alimentos; alimentos integrais. 


\section{INTRODUÇÃO}

São inúmeros os benefícios que as fibras alimentares trazem para a saúde humana: promoção do equilíbrio da microbiota intestinal; adequação do funcionamento do trato digestório; contribuição para a redução de doenças crônicas não transmissíveis, o que the inclui na categoria de alimento funcional, ou seja, há uma relação benéfica entre a ingestão do alimento com a redução de risco de uma condição relacionada à saúde, porém hábitos de vida saudáveis e ingestão de uma dieta equilibrada devem estar juntos (MARTINO; COSTA; RODRIGUES, 2016).

Para Paula, Marques e Chauld (2009) é indispensável que a população seja estimulada a incluir diariamente a ingestão de fibras alimentares, buscando a prevenir e/ou reduzir alguns problemas de saúde, a fim de evitar tratamentos invasivos, como por exemplo, o uso de medicações. Uma alternativa seria a utilização de fibras alimentares, provenientes, por exemplo, de frutas, verduras e até mesmo de produtos industrializados em que são adicionadas. Quando usadas em quantidades e período adequado, as fibras alimentares garantem benefícios.

Segundo a Associação Brasileira das Indústrias de Biscoitos, Massas Alimentícias, Pães e Biscoitos Industrializados - ABIMAPI (2017/2018), a aceitação de massas alimentícias é alta (95\%) por ser considerada uma preparação prática, nutritiva e de sabor agradável, além de ser um produto minimamente processado.

O Guia Alimentar para a População Brasileira recomenda que alimentos in natura ou minimamente processados seja à base da alimentação e conforme a classificação, o macarrão é considerado um alimento minimamente processado, pois é submetido a alterações mínimas. A rapidez no preparo e a diversidade que promove à alimentação é a sua principal característica culinária. Dispõe de diferentes tipos e formas além de ser compatível com diversos acompanhamentos. Salienta-se que o macarrão "instantâneo" é considerado um alimento ultraprocessado que deve ser evitado (BRASIL, 2014). Diante do estilo de vida atual, as empresas têm buscado novos produtos, estes desenvolvidos com valor nutricional agregado buscando assim melhorar aspectos nutricionais na alimentação (TOMICKI. et al.,2015). As fibras alimentares são boas opções para serem acrescentadas em massas alimentícias, pois proporciona efeitos positivos à saúde humana, trazendo inúmeros benefícios, como redução dos riscos de doenças crônicas não transmissíveis (MARTINO; COSTA; RODRIGUES, 2016).

A Resolução da Diretoria Colegiada - RDC no 263 de 22 de dezembro de 2005 define massa alimentícia como um produto obtido da farinha de trigo (Triticumaestivum L. e ou de outras espécies do gênero Triticum) e/ou derivados de trigo durum (Triticumdurum L.) e/ ou provenientes de outros cereais, leguminosas, raízes e/ou tubérculos, resultantes do método de empasto e amassamento mecânico, sem fermentação. Outros ingredientes podem ser adicionados isoladamente ou combinados à massa, desde que não haja descaracterização do produto, podendo ser apresentado seco, fresco, pré-cozidos, instantâneos ou prontos para o consumo, com diferentes formas e recheios (BRASIL, 2005).

Na busca por alimentos saudáveis é essencial que haja compreensão do que está exposto nos rótulos. Toloni et al. (2016) destacam que a rotulagem nutricional dos alimentos é um excelente instrumento de conhecimento e pode ser utilizada 
em prol da promoção de uma alimentação saudável. A clareza das informações nos rótulos colabora para escolhas mais criteriosas e conscientes a respeito dos alimentos e para a Política Nacional de Alimentação e Nutrição - PNAN (BRASIL, 2013), a rotulagem nutricional constitui-se como instrumento central no aperfeiçoamento do direito à informação. Este acesso à informação fortalece a capacidade de análise e decisão do consumidor, portanto, é indispensável que essa ferramenta seja acessível e correta para facilitar no momento da escolha por alimentos mais saudáveis.

Apesar do avanço nas normas obrigatórias de rotulagem nutricional, é possível ainda se deparar com informações excessivamente técnicas e publicitárias que podem induzir à interpretação equivocada (BRASIL, 2013).

Atualmente, tramita o projeto de lei $n^{\circ} 4643 / 19$, que pretende alterar o Decreto-lei no 986/69, que dispõe sobre as normas básicas para alimentos, esta modificação visa adotar um modelo frontal de rotulagem para alimentos embalados, de modo à complementar a tabela nutricional (BRASIL, 2019).

Diante do exposto, o objetivo deste estudo foi analisar as informações nutricionais de macarrões integrais quanto à composição de fibras presentes na informação nutricional, bem como, quanto à adequação conforme as legislações vigentes que norteiam informações obrigatórias em rótulos de alimentos. Levando-se em conta ainda, a carência de estudos com este alimento, ressalta-se a importância do presente trabalho.

\section{MATERIAIS E MÉTODOS}

Esta pesquisa tem caráter descritivo de abordagem quantitativa. As amostras de macarrões integrais foram adquiridas na qualidade de consumidor nos principais supermercados da cidade de Fortaleza-CE, localizados em ruas de grande movimento e de fácil acesso pertencentes a todas as regionais da cidade no mês de janeiro de 2019. As regionais da cidade de Fortaleza estão divididas conforme mapa específico (IPECE, 2007). No total, 35 supermercados foram visitados.

No presente estudo, foram analisados 24 rótulos de macarrões integrais dos tipos: penne, espaguete, farfalle (laços), tortelline tricolori, parafuso, ninho e talharim, referente a 21 marcas. De modo que foi necessário utilizar produtos de uma mesma marca com especificações distintas, pois estes continham valores diferentes de fibras.

O critério de seleção adotado para a aquisição dos produtos foi à denominação "integral" descrita nas embalagens dos macarrões e o critério de exclusão foram os que apresentassem porção inferior ou superior a $80 \mathrm{~g}$. A visualização da porção é representada na Tabela 1.

Rótulos de diferentes marcas de macarrões integrais foram avaliados quanto às quantidades de fibras demonstradas em seus rótulos. Baseado na recomendação da ingestão diária de fibras de um adulto (como mostra o percentual de valor diário - \%VD da informação nutricional) (BRASIL, 2003) buscouse comparar estes valores entre as amostras e identificar qual tipo de macarrão possui maior teor deste componente. 
Além disso, verificou-se a adequação da denominação "alto conteúdo de fibra" e "fonte de fibra", isto de acordo com a Resolução no 54/12 (BRASIL, 2012) que dispõe sobre o regulamento técnico sobre informação nutricional complementar e informações obrigatórias.

Tabela 1. Tabela demonstrativa da estrutura de uma informação nutricional com nutrientes e informações obrigatórias e porção de 80 gramas exigida para um rótulo de macarrão

\section{Informação Nutricional}

Porção de $80 \mathrm{~g}$ (Medida caseira)

Quantidade por porção $\% \mathrm{VD}(*)$

Valor energético

Carboidratos

Proteína

Gorduras totais

Gorduras saturadas

Gorduras trans

Fibras alimentares

Sódio

*\% Valores Diários com base em uma dieta de $2.000 \mathrm{kcal}$ ou 8400 kJ. Seus valores diários podem ser maiores ou menores dependendo de suas necessidades energéticas.

FONTE: RDC $n^{\circ} 360 / 03$ e RDC $n^{\circ}$ 359/03 (BRASIL, 2003).

Produtos com origem em outros países foram adquiridos, considerando a tradução das informações nutricionais fixadas em etiquetas nas embalagens. Salienta-se que conforme a Resolução no 259/02 é necessário que as informações obrigatórias sejam descritas no idioma oficial do país de consumo (BRASIL, 2002).

Foram avaliados também se os rótulos estavam de acordo com a Resolução no 259/02 da ANVISA que inclui os princípios gerais e informações obrigatórias em um rótulo. Os itens estão descritos na Tabela 2.

Tabela 2. Princípios gerais e informações obrigatórias de um rótulo

Denominação de venda do produto
Nome da razão social
Identificação do lote e da origem
Lista de ingredientes
Conteúdo líquido
Prazo de validade
Instruções de preparo.

FONTE: RDC $n^{\circ}$ 259/02 (BRASIL, 2002)

Elaborou-se um questionário de acordo com os itens exigidos na tabela 2 para a coleta dos dados.

A Resolução no 360/03 referente à informação nutricional (valor energético, carboidratos, proteínas, gorduras totais, saturadas, gorduras trans, fibras 
alimentares), idioma, localização, porção, medida caseira, percentual de valor diário (\%VD) (BRASIL, 2003) também foi verificada nas amostras.

Finalmente, verificou-se a aplicação da Lei 10.674/03 referente à obrigação da disposição da expressão "contém glúten" ou "não contém glúten" e suas especificidades nos rótulos (BRASIL, 2003).

Construiu-se uma tabela com a quantidade da média e desvio padrão das fibras encontradas nas informações nutricionais dos rótulos de macarrões integrais e um gráfico com percentual de itens em conformidade e itens não conformes de acordo com a RDC no 259/02 (BRASIL, 2002).

\section{RESULTADOS E DISCUSSÃO}

Apenas uma marca de macarrão foi excluída, pois apresentava a porção de 50g sendo que para massas alimentícias secas a RDC no 359/03 define a porção de 80g (BRASIL, 2003), inviabilizando, desta forma, a comparação com as demais amostras no tocante ao conteúdo dos nutrientes por porção.

De acordo com a RDC no 54/12 (BRASIL, 2012) que dispõe sobre informações nutricionais complementares, tais como a atribuição da denominação "alto conteúdo de fibra" e "fonte de fibra", todas as amostras atenderam aos critérios de classificação que estabelece o teor mínimo de $2,5 \mathrm{~g}$ de fibra por porção no alimento para o uso da alegação "fonte de fibra" e o teor mínimo de $5 \mathrm{~g}$ por porção para o uso da alegação "alto conteúdo de fibra".

$\mathrm{Na}$ Tabela 3 estão dispostas as quantidades de fibras encontradas nos rótulos, correspondendo à porção referida na embalagem do macarrão integral $(80 \mathrm{~g})$. Verificou-se que $70,8 \%(n=17)$ dos rótulos dos produtos atendiam aos critérios para alegação de "alto conteúdo" obtendo-se uma média de 5,43g. Valor relevante, uma vez que essa quantidade corresponde a $21,72 \%$ do que é recomendada para o consumo diário de um indivíduo adulto $(25 \mathrm{~g} / \mathrm{dia})$. Com relação ao valor indicado do consumo diário de fibras para o público infantil temos um resultado também relevante, pois a recomendação da Dietary Reference Intakes (IOM, 2011) é de $19 \mathrm{~g}$ a $25 \mathrm{~g}$ por dia para crianças de 1 a 8 anos o que corresponde a $28,57 \%$ do consumo diário.

De acordo com a Tabela Brasileira de Composição de alimentos - TACO (NEPA, 2011) na porção de $100 \mathrm{~g}$ do macarrão trigo cru existem $2,9 \mathrm{~g}$ de fibra. Já, segundo Filisetti-Cozzi (1991) existem apenas 1,20g de fibra na porção de $100 \mathrm{~g}$ de macarrão comum cozido. Em um estudo realizado com pães integrais por Silva, Gallon e Theodoro (2014) a média de fibra na porção $(50 \mathrm{~g})$ encontrada foi de $2,95 \mathrm{~g}$, valor inferior ao identificado nesta pesquisa.

O maior índice de fibra foi de 8,0g na porção em duas amostras (1 e 4), sendo que em uma delas havia presença de chia em sua composição e o outra trata-se de uma massa de sêmola durum (produto obtido através do processo de moagem do grão beneficiado), mas sem a adição de ingredientes com fibra. Segundo Silva et al. (2016), a chia é uma boa fonte de fibra alimentar principalmente insolúvel e sua ingestão contribui para acelerar o trânsito intestinal devido à quantidade de fibras insolúveis, o que auxilia no aumento do volume fecal. O grão absorve água e forma um gel (mucilagem) promovendo saciedade, diminuindo desta forma o consumo energético e favorecendo o controle glicêmico. Salienta-se, ainda, que a chia 
apresenta altas concentrações de ácidos graxos do tipo alfa-linolênico, atuando no organismo na prevenção e no tratamento de doenças não transmissíveis como obesidade, hipertensão arterial e dislipidemia.

Tabela 3. Quantidade de fibras apresentadas em rótulos de macarrões integrais.

\begin{tabular}{cr} 
Macarrões Integrais & Fibras \\
\hline Amostra 1 & $8,0 \mathrm{~g}$ \\
Amostra 2 & $7,4 \mathrm{~g}$ \\
Amostra 3 & $7,1 \mathrm{~g}$ \\
Amostra 4 & $8,0 \mathrm{~g}$ \\
Amostra 5 & $7,0 \mathrm{~g}$ \\
Amostra 6 & $5,6 \mathrm{~g}$ \\
Amostra 7 & $6,4 \mathrm{~g}$ \\
Amostra 8 & $6,0 \mathrm{~g}$ \\
Amostra 9 & $6,0 \mathrm{~g}$ \\
Amostra 10 & $5,9 \mathrm{~g}$ \\
Amostra 11 & $4,5 \mathrm{~g}$ \\
Amostra 12 & $5,6 \mathrm{~g}$ \\
Amostra 13 & $5,5 \mathrm{~g}$ \\
Amostra 14 & $5,4 \mathrm{~g}$ \\
Amostra 15 15 & $5,2 \mathrm{~g}$ \\
Amostra 16 & $5,0 \mathrm{~g}$ \\
Amostra 17 & $5,0 \mathrm{~g}$ \\
Amostra 18 & $5,0 \mathrm{~g}$ \\
Amostra 19 & $4,4 \mathrm{~g}$ \\
Amostra 20 & $4,4 \mathrm{~g}$ \\
Amostra 21 & $3,8 \mathrm{~g}$ \\
Amostra 22 & $3,4 \mathrm{~g}$ \\
Amostra 23 & $3,2 \mathrm{~g}$ \\
Amostra 24 & $2,7 \mathrm{~g}$ \\
\hline Média (Desvio Padrão) & $5,43 \mathrm{~g}(1,49)$ \\
\hline & \\
\hline
\end{tabular}

FONTE: Autoras

De acordo com a RDC no 54 de novembro de 2012, para o alimento ser considerado fonte de fibra é necessário apresentar obrigatoriamente no mínimo 2,5 g por porção de fibra, já para ser classificado como alto conteúdo de fibra deve ofertar no mínimo $5 \mathrm{~g}$ de fibra por porção (BRASIL, 2012). No presente estudo, observou-se que $70,8 \%$ ( $n=17$ ) dos macarrões integrais analisados são classificados como alto conteúdo de fibra dispondo de 5 a $8 \mathrm{~g}$ de fibras por porção e $29,1 \%$ ( $n=7)$ classificados como fonte ofertando de $2,7 \mathrm{~g}$ a $4,5 \mathrm{~g}$ de fibras por porção. Um estudo realizado por Sousa et al. (2015) para avaliar o teor de fibras em 20 barras de cereais em versão tradicional verificou que apenas $20 \%(n=4)$ poderiam utilizar a alegação "fonte de fibra", já que as demais amostras não atendiam aos critérios de classificação da legislação. Ferraz, Cruz e Freitas (2016) encontraram em seu estudo $85 \%$ das marcas de pães integrais e pães sem glúten classificados de acordo com a RDC no 54/12 como fonte de fibras. Já Leite e Lenquiste (2017) obtiveram adequação de $100 \%$ dos rótulos de pães integrais quanto a esta legislação ao contrário do presente estudo que não atingiu este patamar de adequação. Desta forma, esses resultados demonstram que são necessárias fiscalizações atuantes 
para que as normas estabelecidas nas legislações sejam realmente cumpridas e as informações nutricionais passadas corretamente ao consumidor.

$\mathrm{Na}$ lista de ingredientes da amostra 22 havia um "mix" de farinhas (trigo, soja, aveia, centeio, linhaça, cevada, girassol e gergelim) e mesmo assim, a oferta foi de apenas $3,4 \mathrm{~g}$ de fibra na porção, identificando-o somente como macarrão integral fonte de fibra, evidenciando com isto o quanto é importante observar os rótulos e entender que estes ingredientes não fazem do produto aquele que tem alto conteúdo de fibras, porém, ainda assim seria uma opção preferível em relação ao macarrão tradicional, como por exemplo, o macarrão de sêmola, uma vez que este apresenta valor inferior de fibra na porção.

Entre as amostras coletadas no presente estudo (amostras 19, 23 e 24), identificaram-se massas alimentícias integrais que podem ser consumidas por um grupo específico de consumidores, os celíacos. Segundo Araújo et al. (2010) a Doença Celíaca (DC) é uma patologia considerada autoimune desencadeada pelo consumo de alimentos constituído com glúten por indivíduos suscetíveis geneticamente. Para que a doença se manifeste, também é necessária a presença de condições ambientais e imunológicas.

Conforme Araújo et al. (2010) para assegurar a exclusão total do glúten na dieta, é fundamental observar detalhadamente as descrições de todos os ingredientes e informações nutricionais complementares presente nos rótulos. A oferta de alimentos específicos para este público é restrita.

Segundo a Lei 10.674/03 que exige as inscrições "contém glúten" ou "não contém glúten", impresso, todos os rótulos $100 \%(n=24)$ estavam de acordo com a legislação. O mesmo foi verificado em um estudo realizado por Zorzanello e Weschenfelder (2017) em que 100\% ( $n=18)$ das embalagens de pães estavam conforme o recomendado por lei, alertando sobre a presença de glúten. As informações foram expostas com as letras em destaque, de forma nítida e de fácil leitura.

Nesta pesquisa foram identificadas três amostras de macarrões integrais sem glúten sendo duas do tipo parafuso e um talharim, elaborados a base de arroz (amostras 19, 23 e 24). A quantidade de fibras nestas amostras variou de 2,7g a $4,4 \mathrm{~g}$ por porção de $80 \mathrm{~g}$, tratando-se de opções de consumo para quem não tolera a proteína do trigo.

Um gráfico foi elaborado a respeito das conformidades e não conformidades segundo a legislação de rotulagem de produtos alimentícios: RDC no 259/02 (BRASIL, 2002). Das 24 amostras analisadas, apenas seis marcas apresentaram não conformidades em alguns itens da legislação descritos posteriormente.

A rotulagem de alimentos embalados é redigida pela RDC no 259/02, que define alguns princípios essenciais que devem ser descritos ou apresentados nos rótulos (BRASIL, 2002). Esta legislação não foi completamente seguida nas amostras analisadas, e apresentou números superiores (31\%) de inconformidade se comparado com a RDC no 360/03 que foi de apenas $4 \%$.

Os tópicos não seguidos de maneira correta na RDC no 259/02 (BRASIL, 2002) são os seguintes: $8 \%(n=2)$ da amostra utilizaram sinais, símbolos, emblemas, ilustrações ou outras representações gráficas que podem tornar a informação incorreta, induzindo o consumidor ao equívoco como emprego de sinais de positivo (+) na embalagem dando a ideia de adição de determinados nutrientes 
nos produtos e o uso do número $100 \%$, potencializando uma especificação do produto. Miranda et al. (2017) avaliaram 23 rótulos de pães de fôrma e verificouse que $26 \%$ continham frases, vocábulos ou desenhos que apresentavam falso conceito sobre vantagem e segurança em relação a produtos semelhantes, induzindo o comprador à falha ou engano. Smith e Almeida-Muradian (2011) analisaram os seguintes rótulos: Sobremesas congeladas, picolés, sorvetes, iogurtes e leite fermentados, leites em pó e UHT, chocolate ao leite e branco, bombons, biscoitos, alimentos à base de soja, repositores hidroeletrolíticos e repositores energéticos, alimentos específicos para o público infantil (cereais e alimentos para nutrição enteral ou oral), identificaram que $30,8 \%$ dos rótulos apresentaram frases que não estão previstas nos regulamentos técnicos e que podem induzir o consumidor ao erro. Observaram também que $32,7 \%$ dos rótulos, apresentaram ilustrações que não satisfaziam à composição do alimento além de figuras e símbolos.

Marzarotto e Alves (2017) realizaram um estudo em um estabelecimento comercial do ramo de hortifruti em Caxias do Sul-RS sobre a leitura dos rótulos, em que a maioria dos consumidores referiram localizar as informações nutricionais, porém, dizem que para realizar as escolhas adequadas na alimentação o conhecimento que possuem não é suficiente.

Em outro estudo transversal realizado em 23 supermercados por Souza et al. (2011) na cidade de Natal em 2008, com 368 adultos e com média de idade de 40,99 anos, observou-se que $96,8 \%$ dos consumidores entrevistados declararam que as informações nutricionais são relevantes, mas $46,6 \%$ mencionaram compreendê-las parcialmente e apenas 3,8\% declararam entendê-las totalmente. Porém, 3,9\% não confiam nas indicações dos rótulos levando assim os consumidores a não observarem a informação nutricional, além de desmotivá-los em relação à análise dos rótulos.

Conforme a RDC no 259/02(BRASIL, 2002) não devem constar ou apresentar no rótulo de alimentos embalados citações que indiquem que o produto possui propriedades medicinais ou terapêuticas e que sua ingestão irá melhorar a saúde. Constatou-se nesta pesquisa que $4 \%(n=1)$ atribuíam efeitos ou propriedades que não possuem ou não podem ser demonstradas, tais como: expõe na embalagem as seguintes frases: " $10 \%$ de fibras" e " alto teor de fibra", sendo que nas informações nutricionais a quantidade de fibra por porção é de 4,4g e a RDC no 54/12 (BRASIL, 2012) preconiza um valor de no mínimo de $5 \mathrm{~g}$ por porção para ser considerado alto conteúdo.

Representando $4 \%(n=1)$ o item em que indica que o alimento possui propriedades medicinais ou terapêuticas, como por exemplo, declaram no rótulo as seguintes frases: "ajuda a regular o intestino e por não conter glúten é de leve digestão" e "o bom funcionamento dos intestinos e uma boa alimentação estão associados à redução de peso". Salienta-se que para a declaração em um rótulo de uma alegação funcional para as fibras, a mesma deve apresentar-se desta forma segundo a ANVISA (COSTA; ROSA, 2016): "As fibras alimentares auxiliam o funcionamento do intestino. Seu consumo deve estar associado a uma alimentação equilibrada e hábitos de vida saudáveis". Esta alegação pode ser utilizada desde que a porção do produto pronto para consumo forneça no mínimo $3 \mathrm{~g}$ de fibras se o alimento for sólido. Logo, notou-se no presente trabalho que a alegação funcional não foi colocada de modo completamente correto. 
Não apresentaram instruções de preparo ou não estavam redigidas em português 15\% ( $n=4)$ da amostra. De acordo com Machado (2015) quando necessárias, as instruções sobre o preparo, modo adequado de uso, incluindo a reconstituição, o descongelamento ou o tratamento correto do produto, devem ser descritos nos rótulos dos alimentos. Essas instruções devem garantir a utilização correta do alimento e estão preconizadas em resolução. E por fim, $69 \%$ $(n=18)$ das amostras estavam em completa conformidade (Figura 1$)$.

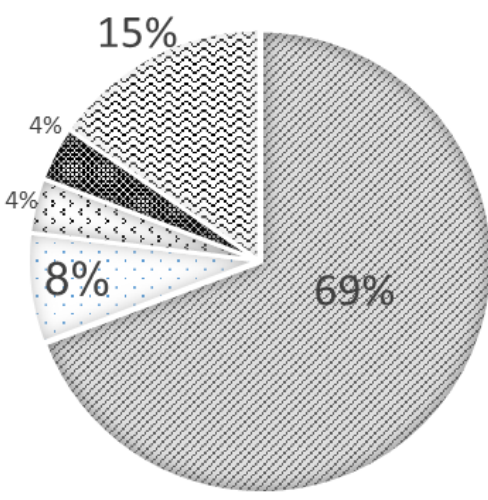

Conformidade

Induz ao equívoco

घ Indica propriedades que não podem ser demonstradas

Indica propriedades medicinais ou terapêuticas

$\approx$ Sem instruções de preparo

Figura 1. Rótulos de macarrões integrais conforme e não conforme de acordo com a legislação RDC no 259/02.

Sobre a RDC 360/2003 que aprova o Regulamento Técnico sobre Rotulagem Nutricional de Alimentos Embalados, tornando obrigatória a rotulagem nutricional, exigindo a declaração do valor energético, carboidratos, proteínas, gorduras totais, gorduras saturadas, gorduras trans e sódio, no presente estudo verificaram-se adequações das informações nutricionais em $96 \%(n=23)$ das amostras com relação à referida legislação e apenas $4 \% \quad(n=1)$ em não conformidade, apresentando letra ilegível, o que possivelmente dificultaria o consumidor no momento da aquisição do macarrão. Miranda et al. (2017) obtiveram $34,8 \%$ de inadequação nos rótulos de pães analisados em relação às informações nutricionais. Eles observaram que dos itens insatisfatórios, as inadequações se concentravam no cálculo incorreto que representou $44 \%$, além de 55\% na exposição incorreta da tabela nutricional.

A maior dificuldade enfrentada pelo consumidor é a compreensão dos termos usados, considerados técnicos. Os rótulos dos alimentos simbolizam uma ligação entre o produto e o cliente, entretanto, as informações são entendidas apenas por um grupo em particular, os que têm instruções sobre os dados utilizados nas embalagens. Os consumidores têm como grande desafio compreender os elementos presentes nos rótulos e usá-los de maneira adequada (MARZAROTTO; ALVES, 2017).

As principais resoluções que regulamentam os rótulos são as RDC $n=259 / 02$ e 360/03 da ANVISA (BRASIL, 2012; 2013) sendo capazes de contribuir para escolhas saudáveis na alimentação, portanto, é indispensável que sejam cumpridas nas suas totalidades. Ao se avaliar e conferir informações nas embalagens dos alimentos, 
os consumidores têm a possibilidade de adquirir uma segurança alimentar e nutricional, sendo pertinentes até o ponto em que as informações disponibilizadas forem realmente legítimas e sérias, caso contrário, simplesmente atenderá a uma determinação da legislação e não se comportará como aliados do equilíbrio do consumo alimentar (ARAÚJO, 2017).

Em resumo, a Figura 2 apresenta o percentual de adequação das resoluções analisadas no presente estudo.

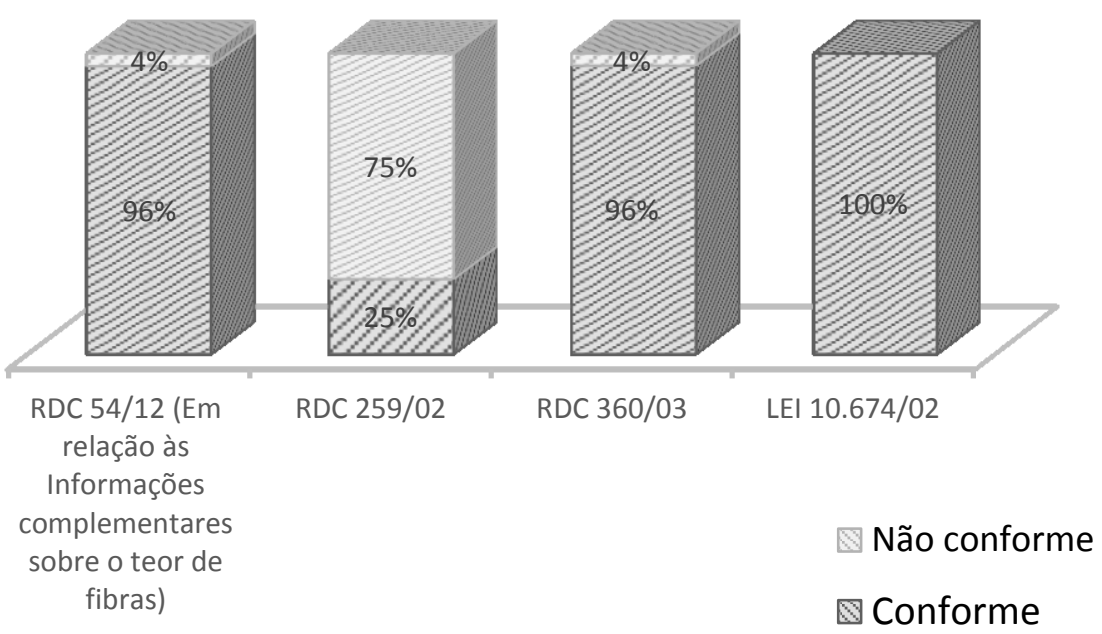

Figura 2. Percentual de adequação dos rótulos de macarrões integrais de acordo com as legislações vigentes analisadas.

Conforme Silva et al. (2012) a contribuição das normas e leis quanto à rotulagem é notória, entretanto são imprescindíveis fiscalizações mais rígidas. Instrumentalizar o consumidor seria uma estratégia inicial para que ele próprio possa exercer a vigilância sobre suas aquisições e, sobretudo, sobre o que consome.

\section{CONCLUSÕES}

Os rótulos de macarrões integrais avaliados nesse estudo, em sua maioria estão em conformidade com as legislações vigentes, no entanto são indispensáveis fiscalizações constantes. A rotulagem nutricional contribui de forma significativa para escolhas saudáveis e adequadas na alimentação, desta forma, faz-se necessário que sejam cumpridas com integralidade.

O estudo das recomendações e legislações abordadas neste trabalho permitiu a melhor compreensão sobre sua importância tanto para o consumidor como para os profissionais de saúde, para que ambos possam fazer melhores escolhas saudáveis no tocante à leitura dos rótulos de macarrões integrais. 


\title{
Analysis of wholemeal pasta labels according to the legislation regarding fiber content and mandatory information
}

\begin{abstract}
Given the development that comes in the food field, you create a need to ensure useful information and use food labels. This stud aimed to analyze whole meal pasta labels in terms of fiber content and mandatory information, according to current legislation. This is a descriptive study with a quantitative approach carried out in the city of Fortaleza-Ceará. Twenty-one brands were analyzed, in which the quantities of fibers described on the labels were observed. A checklist pertaining to the following legislation was developed and applied: RDC n 54/12; RDC no 259/02; RDC no 360/03 and the law 10.674/03. Regarding RDC no 54/12, 70.8\% of the labels analyzed correspond to the claim criterion of "high fiber content" and $29.1 \%$ for "fiber source". Regarding the legislation for packaged foods, seven noncompliant registered trademarks. Inadequate items from the RDC no259/2002 were found: the use of a sign and a name that could lead the consumer to the equivalent; a share of properties that cannot be demonstrated; an indication that it has medicinal or therapeutic properties and a lack of preparation instructions. Regarding RDC no 360/03, only one product presented the illegible letter. Compliance was verified in $100 \%$ of the brands regarding Law 10.674 / 03 , referring to gluten. We concluded that the discount labels, in their majority, are in conformity with the current laws, with 69\% in agreement with RDC no 259/02 and $96 \%$ with RDC no 360/03. Strict inspections are essential, since the consumer needs to have information provided by the products sold.
\end{abstract}

KEYWORDS: Pasta; food labeling; whole food. 


\section{REFERÊNCIAS}

ABIMAPI. Associação Brasileira das Indústrias de Biscoitos, Massas Alimentícias e Pães e Biscoitos Industrializados. Massas Alimentícias. 2017/2018, cap. 3. Disponível em: <https://www.abimapi.com.br/anuario/pdf/Cap3.pdf>. Acesso em: 16 mai. 2019.

ARAÚJO, H. M. C. et al. Doença celíaca, hábitos e práticas alimentares e qualidade de vida. Revista de Nutrição, Campinas, n. 23, v.3, p.467- 474, 2010.

ARAÚJO, W. D. R. Importância, estrutura e legislação da rotulagem geral e nutricional de alimentos industrializados no Brasil. Revista Acadêmica Conecta FASF. v. 2, n. 1, p. 35-50, 2017.

ASSOCIAÇÃO PORTUGUESA DOS NUTRICIONISTAS - APN. Massas Alimentícias, uma abordagem técnica e cientifica. E-books APN: № 35, outubro de 2014. Disponível em: <E-books APN: №35, outubro de 2014>. Acesso em: 16 mai. 2019.

BRASIL. Projeto de lei $n^{\circ} 4643$, de 08 de maio de 2019. Altera o Decreto-Lei no 986, de 21 de outubro de 1969. Normas básicas sobre alimentos. Brasília, DF, 2019. Disponível em:

https://www.camara.leg.br/proposicoesWeb/prop_mostrarintegra?codteor=179 4625\&filename=Tramitacao-PL+4643/2019. Acesso em: 06 de maio de 2020.

BRASIL. Ministério da Saúde. Secretaria de Atenção à Saúde. Guia alimentar para a população brasileira. Brasília (DF): 2014; 154p.

BRASIL. Agência Nacional de Vigilância Sanitária - ANVISA. A Resolução RDC no 263, de 22 de dezembro de 2005. Regulamento Técnico para Produtos de Cereais, Amidos, Farinhas e Farelos. Diário Oficial da União. Poder Executivo, Brasília, DF, de 23 de setembro de 2005.

BRASIL. Ministério da Saúde. Informação Nutricional. Resolução RDC no 360, de 23 de dezembro de 2003. Aprova o Regulamento Técnico sobre Rotulagem Nutricional de Alimentos Embalados. Diário Oficial da República Federativa do Brasil. Poder Executivo. Brasília, DF, 26 de dez. 2003b. Seção 1.

BRASIL. Ministério da Saúde. Regulamento. Resolução RDC no 54, de 12 de novembro de 2012. Técnico sobre Informações Nutricional Complementar. Agência Nacional de Vigilância Sanitária - ANVISA. Disponível em: <http://portal.anvisa.gov.br/documents/\%2033880/2568070/rdc0054_12_11_20 12.pdf/c5ac23fd-974e-4f2c-9fbc-48f7e0a31864>. Acesso em: 10 mai. 2019. 
BRASIL. Ministério da Saúde. Secretaria de Atenção à Saúde. Departamento de Atenção Básica. Política Nacional de Alimentação e Nutrição. Ministério da Saúde, Secretaria de Atenção à Saúde. Departamento de Atenção Básica. Básica. - 1. ed., 1. reimpr. - Brasília: Ministério da Saúde, 2013. 84 p. Disponível em: <http://bvsms.saude.gov.br/bvs/publicacoes/politica_nacional_alimentacao_nut ricao.pdf>. Acesso em: 14 mai. 2019.

BRASIL. Ministério da Saúde. Secretaria de Vigilância Sanitária. Portaria no 132, de 19 de fevereiro de 1999. Diário Oficial da União; Poder Executivo, de 25 de fevereiro de 1999.

COSTA, N. M. B.; ROSA, C. O. B. Alimentos funcionais: componentes bioativos e efeitos fisiológicos. 2. ed. Rio de Janeiro: Rubio, 2016.

FERRAZ, E. C; CRUZ, M.M; FREITAS, E. C. Avaliação dos rótulos de diferentes marcas de pães integrais versus pães sem glúten comercializados no município de Vitória da conquista - B A. C\&D - Revista Eletrônica da Fainor, Vitória da Conquista, v. 9, n. 1, p. $46-55,2016$.

FILISETTI-COZZI, T. M. C.C.; LAJOLO, F. M. Fibras alimentares insolúveis, solúvel e total em alimentos brasileiros. Revista de Farmácia e Bioquímica. Univ. São Paulo, v 27, n. 1, p. 85-99, 1991.

IOM - INSTITUTE OF MEDICINE. DietaryReferencelntakesforenergy, carbohydrate, fiber, fat, fattyacids, cholesterol, protein, and amino acids. Washington, D.C.: NationalAcademy Press, 2011. Disponível em: <http://nationalacademies.org/hmd/ /media/Files/Activity\%20Files/Nutrition/D RI-Tables/8_Macronutrient\%20Summary.pdf?la=en>. Acesso em: 10 de mai. 2019.

IPECE. Instituto de Pesquisa e Estratégias Econômicas do Ceará. Ceará em mapas. 2007. Fortaleza- Ce. Disponível em: http://www2.ipece.ce.gov.br/atlas/capitulo1/11/140x.htm. Acesso em: 06 de maio de 2019.

LEITE, A. B; LENQUISTE, S. A. Rotulagem nutricional de pães integrais: análise e conhecimento dos consumidores. Revista Colloquium Vitae, v. 9, n. especial, p.150 - 157. 2017.

MARTINO, H. S. D.; COSTA, N.M.; RODRIGUES, F. C. Fibras Alimentares. In: COSTA, N. M. B.; ROSA, C. O. B. Alimentos funcionais: componentes bioativos e efeitos fisiológicos. 2. ed. Rio de Janeiro: Rubio, 2016. 
MARZAROTTO, B.; ALVES, M. K. Leitura de rótulos de alimentos por frequentadores de um estabelecimento comercial. Revista Ciência \& Saúde, v. 10, n.2, p. 102-108. 2017.

MIRANDA, L. L. S. et al. Análise da rotulagem nutricional de pães de forma com informação nutricional complementar comercializados no município de Belo Horizonte - MG.HU Revista, Juiz de Fora, v. 43, n. 3, p. 211 -217, 2017.

NASCIMENTO, J. M.; SOUZA, A. O. Avaliação das informações nutricionais e ingredientes declarados em rótulos de pães integrais comercializados em supermercados de Belém, Pará. Demetra: alimentação, nutrição \& saúde, v.13, n.4, p. 793-817, 2018.

NÚCLEO DE ESTUDOS E PESQUISA EM ALIMENTOS - NEPA. Tabela Brasileira de Composição de Alimentos- TACO. 4. ed. rev. e amp. Campinas: NEPA UNICAMP, 2011.

PAULA, L. D.; MARQUES, C. F.; CHAULD, S. G. Efeitos produzidos pela ingestão de fibras alimentares: solúveis e insolúveis em camundongos. Revista Ciência et PRAXIS, v. 2, n. 3, 2009.

SILVA, B. P. et al. Chia: Aspectos Nutricionais e Funcionais. In: COSTA, N. M. B.; ROSA, C. O. B. Alimentos funcionais: componentes bioativos e efeitos fisiológicos. 2. ed. Rio de Janeiro: Rubio, 2016.

SILVA, L. M. M. et al. Avaliação da Rotulagem de Alimentos com Base nos Parâmetros Nutricionais e Energéticos. Revista Verde, Mossoró - RN, v.7, n.1, p. 04-10,2012.

SILVA, V. C. P.; GALLON, C. W.; THEODORO, H. Avaliação das rotulagens nutricionais dos pães integrais: fibras, sódio e adequação com a legislação vigente. Demetra, v. 9, n.4, p. 985-1001, 2014.

SMITH, A. C. L.; ALMEIDA-MURADIAN, L. B. Rotulagem de alimentos: avaliação da conformidade frente à legislação e propostas para a sua melhoria. Revista do Instituto Adolfo Lutz. São Paulo, v. 70, n. 4, p. 463-72, 2011.

SOUSA, A. M. et al. Avaliação da rotulagem nutricional e teor de fibras alimentares de barras de cereais.Revista Saúde Pública de Santa Catarina, Florianópolis, v. 8, n. 1, p.714, 2015. 
SOUZA, S. M. F. C. et al. Utilização da informação nutricional de rótulos por consumidores de Natal, Brasil. Revista Pan-Americana de Saúde Pública, v. 29, n. 5, p. 337 - 343, 2011.

TOLONI, M. H. A.et al. Rotulagem e Publicidade de Alimentos. In: TADDEI, J. A. et al. Nutrição em Saúde Pública. 2 ed. Rio de Janeiro: Rubio, 2016.

TOMICKI. et al. Elaboração e avaliação da qualidade de macarrão isento de glúten. Revista Ciência Rural, v.45, n.7, jul, 2015.

ZORZANELLO, B. M.; WESCHENFELDER, S. Pães produzidos em escala industrial e comercializados coma denominação de "integral": análise da rotulagem e identificação dos ingredientes integrais e aditivos C\&D - Revista Eletrônica da Fainor, Vitória da Conquista, v.10, n.3, p. 407-423, 2017.

SALES, A. P. B. S.; RODRIGUES, W. B. C.; PESSOA, P. P. Análise de rótulos de macarrões integrais de acordo com a legislação em relação ao teor de fibra e informações obrigatórias. Brazilian Journal of Food Research, Campo Mourão, v. 10, n. 2, p. 143-157, abr.jun. 2019. Disponível em: https://periodicos.utfpr.edu.br/rebrapa

Correspondência:

Priscila Pereira Pessoa

Centro Universitário Fametro, Unifametro, Rua Conselheiro Estelita, n 500, Centro, CEP 60010-260 Fortaleza, Ceará, Brasil.

Direito autoral: Este artigo está licenciado sob os termos da Licença Creative Commons-Atribuição 4.0 Internacional. 